УДК 655.3.062

\title{
СТРУКТУРНА ОРГАНІЗАЦІЯ \\ ПРОГРАМНО-ТЕХНІЧНИХ ЗАСОБІВ \\ ЦИФРОВОГО КОНТРОЛЮ \\ ЯКОСТІ КОЛЬОРОВІДТВОРЕННЯ
}

๑ П. О. Киричок, д.т.н., професор, В. В. Морфлюк-Щур, аспірантка, НТУУ «КПІ», Київ, Україна

В статье предложена структурная организация программнотехнических средств контроля качества цветопередачи, которые базируется на автоматизации процесса измерения, обработки и анализа цветовых параметров оттиска.

The article is devoted to the structural organization of software and hardware for digital control of quality of color reproduction, which is based on the process of automation measurement, and analyze the color settings of sheet.

\section{Постановка проблеми}

Сучасні принципи організації процесів цифрового контролю якості кольоровідтворення офсетного способу друку потребують інтеграції значної кількості процесів обробки та перетворення інформації результатів вимірювання характеристик кольору у реальному масштабі часу [1], що вимагає розробки та впровадження нових підходів та методів для іх реалізації на основі сучасних програмнотехнічних засобів автоматизації процесів, для яких взаємодія програмного середовища із зовнішнім по відношенню до неї процесом вимірювання характеристик кольору та внутрішнім процесом визначення якості кольоровідтворення повинна забезпечувати мінімізацію часу для обробки та формування множини характеристик 3 використанням уніфікації засобів програмного керування.
Це визначає подальший напрямок розробки та структурної організації програмно-технічних засобів автоматизації процесів технологічного контролю якості продукції та побудови на їх основі автоматизованих систем контролю.

\section{Аналіз попередніх досліджень}

Аналіз сучасного стану процесів контролю якості кольоровідтворення для офсетного способу друку характеризується застосуванням двох методів визначення характеристик кольору: денситометричний і колориметричний $[2,3]$. Вказані методи базуються на основі ергатичного підходу для побудови вимірювальних систем. Денситометричні вимірювання дозволяють визначати та корегувати товщину фарбового шару на основі вимірювання оптичної густини, а спектрофотометричні вимірювання надають можливість ана- 
лізувати характеристики кольору, які якісно і кількісно відповідають колірному сприйняттю людиною, та виконуються на основі приладів (спектрофотометрів), які конструктивно орієнтовані на автоматизацію процесів вимірювання та обробки, що надає перспективи структурної побудови програмно-технічних засобів для автоматичного управління контролем якості кольоровідтворення друку.

Застосування спектрофотометричних засобів та методів вимірювання на основі програмно-технічних засобів керування кольором надає можливість зменшити кількість вимірів і відповідних корегувань друкарського процесу в декілька разів порівняно з використанням денситометричних засобів вимірювання [2].

\section{Мета роботи}

Метою даної роботи є розробка та побудова програмнотехнічних засобів цифрового автоматизованого контролю якості кольоровідтворення для офсетного способу друку.

\section{Результати проведених досліджень}

Структурна організація програмно-технічних засобів у системах автоматизації процесів керування цифровим визначенням якості кольоровідтворення офсетного способу друку характеризується уніфікованим порядком виконання етапів, які визначаються логікою контролю якості кольоровідтворення, та може бути представлена структурною схемою рис. 1, для якої етап отримання інфор- мації статистичних вимірювань CVS.cvs Lab координат плашок $\left(L, a^{*}, b^{*}\right)$ з відповідного каналу спектрофотометра під управлінням EOM $€$ одним 3 головних чинників цифрової обробки інформації, що базується на застосуванні програмних засобів перетворення аналогової інформації у цифрову та її обробки і аналізу згідно визначених характеристик кольорових моделей.

Наступні етапи, які необхідні виконати для автоматизації процесів цифрового контролю якості кольоровідтворення визначають наступне:

- запис статистичних вимірювань 3 табличного файлу CVS.cvs у файл Prog.xls;

- статистична обробка та визначення кольорового відхилення $\Delta \mathrm{E}$;

- статистичне визначення похибки кольорового відхилення $\Delta \mathrm{X}$;

- перетворення Lab координат у кольорову модель XYZ;

- визначення розтискування растрових елементів з модифікованих Lab координат;

- побудова графіків розтискування та кольорового охоплення;

- формування звіту якості кольоровідтворення.

Перший та останній етап програмується на основі ергатичного режиму роботи, а інші на основі автоматичної обробки математичних виразів у форматі Microsoft Excel.

Застосування програмно-технічних засобів цифрового контролю якості кольоровідтворення на основі системних програмних засобів реалізації режимів 
проектування прикладного програмного забезпечення дозволяє оптимізувати процеси вимірювання, обробки, аналізу та забезпечити надійність функціонування системи керування кольором в цілому.

Для отримання, обробки та аналізу вимірів розроблено прикладне програмне забезпечення, яке базується на інтеграції програмних засобів ColorPort [4], Microsoft Excel [5] та Visual
Basic for Application [6] та визначає систему керування кольором.

Організація процесів керування технічними засобами вимірювання характеристик кольору базується на застосуванні програмно-керованого обладнання на основі спектрофотометра Eye-OnePro та спеціалізованого програмного забезпечення ColorPort.

Спеціалізоване програмне забезпечення ColorPort (фірми

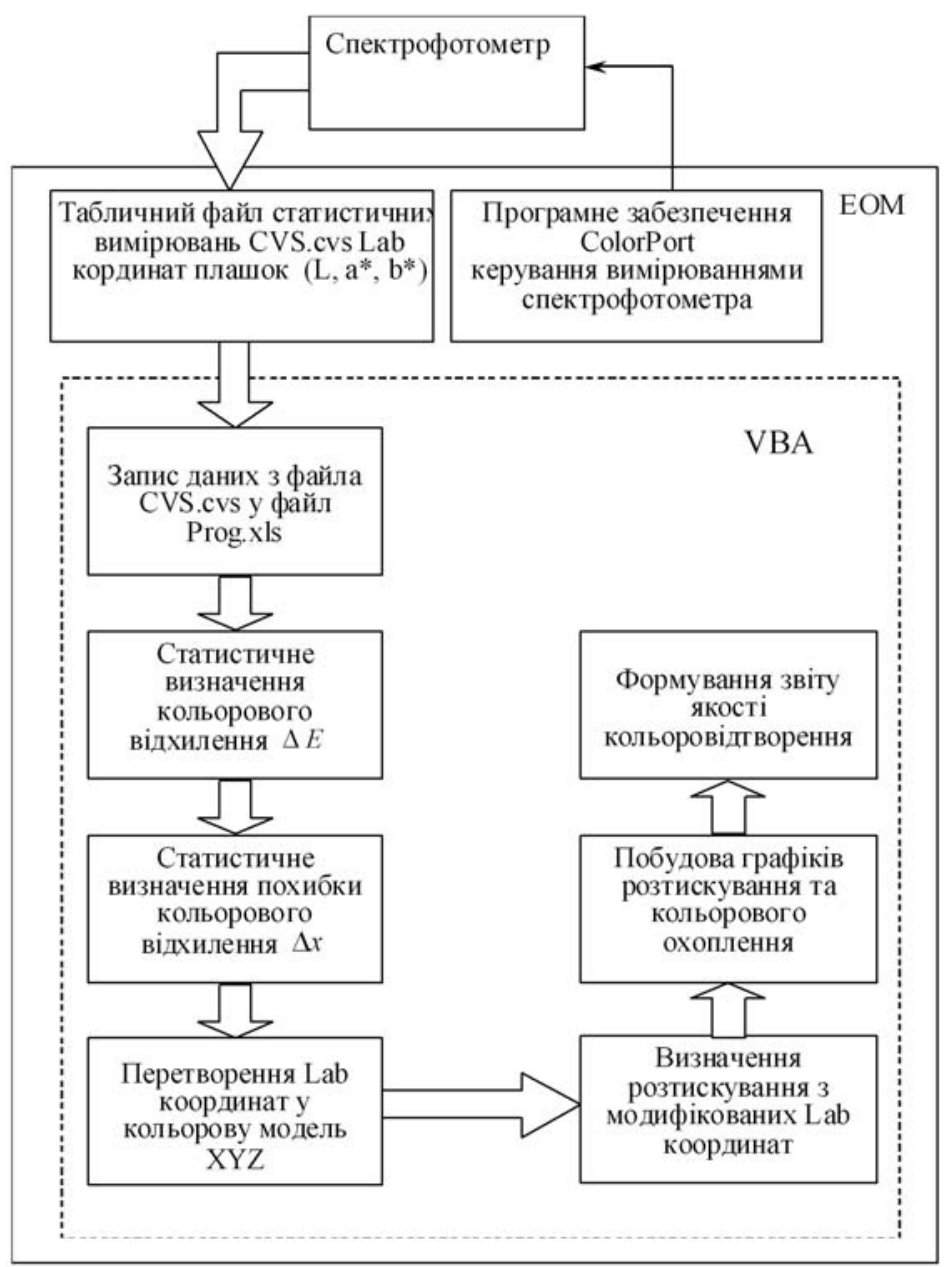

Рис. 1. Структурна схема цифрового визначення якості кольоровідтворення офсетного способу друку 
виробника X-Rite) застосовується для керування спектрофотометром за допомогою інтерактивного режиму та дозволяє створювати, зберігати і вимірювати кольорові шкали для подальшого їх використання в програмах побудови ICC-профілів. За його допомогою створюються файли вимірів, які можна зберігати для програм MonacoPROFILER 4.8 або ProfileMaker 5.0 (використовуються для побудови профілів), та у форматі стандарту CGATS, у вигляді текстового файлу або таблиць даних *.csv, *.xls та інше.

На основі мови Visual Basic for Application побудовано прикладне програмне забезпечення для запису результатів вимірювання з файла CVS.cvs у файл Prog.xls.

Таким чином перші два етапи визначають процеси статистичного вимірювання характеристик кольору та трансформування їх у формат середовища Microsoft Excel, що забезпечує подальший процес автоматизації контролю якості кольоровідтворення.

Для побудови програмних засобів визначення кольорового відхилення $\Delta \mathrm{E}$ та розрахунку похибки вимірювання розроблено прикладне програмне забезпечення на основі середовища Microsoft Excel, в якому побудована уніфікована статистична ідеологія визначення вказаних параметрів згідно опису кольорових характеристик по моделі CIE Lab за змінними аналітичного виразу CIE $\Delta$ E 2000.

Визначені змінні аналітичного виразу CIE $\Delta$ E 2000 послідовно описуються формулами
Microsoft Excel табл. 1, згідно логічної завершеності аналітичних виразів, для забезпечення автоматизації процесу обчислення відповідних значень цих змінних та кольорового відхилення $\Delta \mathrm{E}$.

Для обчислення відповідних значень змінних кольорового відхилення $\Delta \mathrm{E}$ застосовуються виміри Lab координат, що мають три основні складові: $L^{*}-$ світлоту, $a^{\star}$ - червоний і зелений колір, а також $\mathrm{b}^{*}-$ синій і жовтий колір. В застосованих формулах $\mathrm{L}_{2} \mathrm{a}_{2} \mathrm{~b}_{2}$ це виміряні значення з плашок контрольних шкал досліджуваного відбитка виготовленого офсетним способом друку на тиражному папері та відповідно підібраними до технологічного процесу фарбами, a $L_{1} a_{1} b_{1}$ - еталонні значення підібрані з міжнародного галузевого стандарту ISO 12624-2 : 2008 відповідно до вибраних параметрів друку.

Для обчислення відповідних значень параметрів похибки вимірювання для плашок кольорів табл. 2 застосовуються розрахунок середнього значення $\langle x\rangle$ кольорового відхилення для всіх вимірів відповідної плашки, середньої квадратичної похибки $\mathrm{s}_{\mathrm{n}}$, та розрахунку похибки вимірювання $\Delta \mathrm{x}$ на основі систематичної $\Delta \mathrm{x}_{\text {сист }}$ та випадкової по-

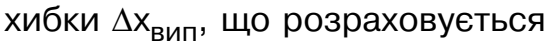
згідно коефіцієнта Стьюдента $t_{\alpha, n}$.

Обчислення відповідних значень розтискування растрових елементів на основі Lab координат виконується шляхом розрахунку інтерпретованої формули Мюрея-Девіса: 
Таблиця 1

Уніфікована програма засобів розрахунку кольорового відхилення для плашок кольорів у середовищі Microsoft Excel

\begin{tabular}{|c|c|c|}
\hline № & Формула Microsoft Excel & Аналітичний вираз згідно з CIE 2000 \\
\hline 1 & $=(\$ B \$ j+H i) / 2$ & $\overline{\mathrm{L}^{\prime}}=\left(\mathrm{L}_{1}+\mathrm{L}_{2}\right) / 2$ \\
\hline 2 & $=\mathrm{KOPEHЬ}\left(\$ C \$ \mathrm{j}^{\wedge} 2+\$ D \$ \mathrm{j}^{\wedge} 2\right)$ & $\mathrm{C}_{1}=\sqrt{\mathrm{a}_{1}^{2}+\mathrm{b}_{1}^{2}}$ \\
\hline 3 & $=K O P E H b\left(l i^{\star} \mid i+J i{ }^{\star} J i\right)$ & $\mathrm{C}_{2}=\sqrt{\mathrm{a}_{2}^{2}+\mathrm{b}_{2}^{2}}$ \\
\hline 4 & $=(\mathrm{Mi}+\mathrm{Ni}) / 2$ & $\overline{\mathrm{C}}=\left(\mathrm{C}_{1}+\mathrm{C}_{2}\right) / 2$ \\
\hline 5 & $\begin{array}{c}=(1-\text { KOPEHЬ }(\text { CTEПЕНЬ }(\mathrm{Oi} ; 7) / \\
\text { /(CTEПЕНЬ }(\mathrm{Oi} ; 7)+ \\
\text { +CTEПЕНЬ }(25 ; 7))) / 2\end{array}$ & $G=\left(1-\sqrt{\frac{\overline{\mathrm{C}}^{7}}{\overline{\mathrm{C}}^{7}+25^{7}}}\right) / 2$ \\
\hline 6 & $=\$ C \$ j^{\star}(1+P i)$ & $a_{1}^{\prime}=a_{1}(1+G)$ \\
\hline 7 & $=l i^{\star}(1+\mathrm{Pi})$ & $a_{2}^{\prime}=a_{2}(1+G)$ \\
\hline 8 & $=K O P E H b\left(Q i^{\star} Q i+\$ D \$ j^{\star} \$ D \$ j\right)$ & $\mathrm{C}_{1}^{\prime}=\sqrt{\mathrm{a}_{1}^{/ 2}+\mathrm{b}_{1}^{2}}$ \\
\hline 9 & $=$ KOPEHЬ $\left(\mathrm{Ri}^{\star} \mathrm{Ri}+\mathrm{Ji}^{\star} \mathrm{Ji}\right)$ & $\mathrm{C}_{2}^{\prime}=\sqrt{\mathrm{a}_{2}^{/ 2}+\mathrm{b}_{2}^{2}}$ \\
\hline 10 & $=(\mathrm{Si}+\mathrm{Ti}) / 2$ & $\overline{\mathrm{C}}^{\prime}=\left(\mathrm{C}_{1}^{\prime}+\mathrm{C}_{2}^{\prime}\right) / 2$ \\
\hline 11 & $\begin{array}{c}=\text { ЕСЛИ(ATAN2(\$D\$j;Qi)>=0; } \\
\text { ГРАДУСЫ(ATAN2(\$D\$j;Qi)); } \\
\text { ГРАДУСЫ(ATAN2(\$D\$j;Qi }))+360)\end{array}$ & $\mathrm{h}_{1}^{\prime}=\left\{\begin{array}{cc}\tan ^{-1}\left(\mathrm{~b}_{1} / \mathrm{a}_{1}^{\prime}\right) & \tan ^{-1}\left(\mathrm{~b}_{1} / \mathrm{a}_{1}^{\prime}\right) \geq 0 \\
\tan ^{-1}\left(\mathrm{~b}_{1} / \mathrm{a}_{1}^{\prime}\right)+360^{\circ} & \tan ^{-1}\left(\mathrm{~b}_{1} / \mathrm{a}_{1}^{\prime}\right)<0\end{array}\right.$ \\
\hline 12 & $\begin{array}{c}=\text { ЕСЛИ(ГРАДУСЫ(ATAN2(Ji;Ri))>=0; } \\
\text { ГРАДУСЫ(ATAN2(Ji;Ri)); } \\
\text { ГРАДУСЫ(ATAN2(Ji;Ri))+360) }\end{array}$ & $\mathrm{h}_{2}^{\prime}=\left\{\begin{array}{cc}\tan ^{-1}\left(\mathrm{~b}_{2} / \mathrm{a}_{2}^{\prime}\right) & \tan ^{-1}\left(\mathrm{~b}_{2} / \mathrm{a}_{2}^{\prime}\right) \geq 0 \\
\tan ^{-1}\left(\mathrm{~b}_{2} / \mathrm{a}_{2}^{\prime}\right)+360^{\circ} & \tan ^{-1}\left(\mathrm{~b}_{2} / \mathrm{a}_{2}^{\prime}\right)<0\end{array}\right.$ \\
\hline 13 & $\begin{array}{l}=\text { ЕСЛИ }(\mathrm{ABS}(\mathrm{Vi}-\mathrm{Wi})>180 \\
(\mathrm{Vi}+\mathrm{Wi}+360) / 2 ;(\mathrm{Vi}+\mathrm{Wi}) / 2)\end{array}$ & $\overline{\mathrm{H}}^{\prime}=\left\{\begin{array}{cc}\left(\mathrm{h}_{1}^{\prime}+\mathrm{h}_{2}^{\prime}+360^{\circ}\right) / 2 & \left|\mathrm{~h}_{1}^{\prime}-\mathrm{h}_{2}^{\prime}\right|>0 \\
\left(\mathrm{~h}_{1}^{\prime}+\mathrm{h}_{2}^{\prime}\right) / 2 & \left|\mathrm{~h}_{1}^{\prime}-\mathrm{h}_{2}^{\prime}\right| \leq 0\end{array}\right.$ \\
\hline 14 & $\begin{array}{c}=1-0,17^{\star} \cos \left((X i-30)^{\star} \Pi И() / 180\right)+ \\
+0,24^{*} \cos \left(2^{\star} \mathrm{Xi}^{\star} \Pi И() / 180\right)+ \\
+0,32^{\star} \cos \left(\left(3^{\star} \mathrm{Xi}+6\right)^{\star} \Pi И() / 180\right)- \\
0,2^{*} \cos \left(\left(4^{\star} \mathrm{Xi}-63\right)^{\star} \Pi И() / 180\right)\end{array}$ & $\begin{array}{l}\mathrm{T}=1-0.17 \cos \left(\overline{\mathrm{H}}^{\prime}-30^{\circ}\right)+ \\
+0.24 \cos \left(2 \overline{\mathrm{H}}^{\prime}\right)+ \\
+0.32 \cos \left(3 \overline{\mathrm{H}}^{\prime}+6^{\circ}\right)- \\
-0.20 \cos \left(4 \overline{\mathrm{H}}^{\prime}-63^{\circ}\right)\end{array}$ \\
\hline
\end{tabular}




\section{ТЕХНОЛОГІЧН І ПРОЦЕСИ}

Закінчення табл. 1

\begin{tabular}{|c|c|c|}
\hline № & Формула Microsoft Excel & Аналітичний вираз згідно з CIE 2000 \\
\hline 15 & $\begin{array}{c}=\text { ЕСЛИ }(\mathrm{ABS}(\mathrm{Wi}-\mathrm{Vi})<=180 ; \mathrm{Wi}- \\
\mathrm{Vi} ; \text { ЕСЛИ }(\mathrm{Wi}<=\mathrm{Vi} ; \mathrm{Wi}-\mathrm{Vi}+360 ; \mathrm{Wi}-\mathrm{Vi}- \\
360))\end{array}$ & $\Delta \mathrm{h}^{\prime}=\left\{\begin{array}{cc}\left(\mathrm{h}_{2}^{\prime}-\mathrm{h}_{1}^{\prime}\right) & \left|\mathrm{h}_{2}^{\prime}-\mathrm{h}_{1}^{\prime}\right| \leq 180^{\circ} \\
\left(\mathrm{h}_{2}^{\prime}-\mathrm{h}_{1}^{\prime}+360^{\circ}\right) & \left|\mathrm{h}_{2}^{\prime}-\mathrm{h}_{1}^{\prime}\right|>180^{\circ}, \mathrm{h}_{2}^{\prime} \leq \mathrm{h}_{1}^{\prime} \\
\left(\mathrm{h}_{2}^{\prime}-\mathrm{h}_{1}^{\prime}-360^{\circ}\right) & \left|\mathrm{h}_{2}^{\prime}-\mathrm{h}_{1}^{\prime}\right|>180^{\circ}, \mathrm{h}_{2}^{\prime}>\mathrm{h}_{1}^{\prime}\end{array}\right.$ \\
\hline 16 & $=\mathrm{Hi}-\$ B \$ \mathrm{j}$ & $\Delta \mathrm{L}^{\prime}=\mathrm{L}_{2}-\mathrm{L}_{1}$ \\
\hline 17 & $=\mathrm{Ti}-\mathrm{Si}$ & $\Delta \mathrm{C}^{\prime}=\mathrm{C}_{2}^{\prime}-\mathrm{C}_{1}^{\prime}$ \\
\hline 18 & $\begin{array}{c}=2^{\star} \operatorname{KOPEH}\left(\mathrm{Si}^{\star} \mathrm{Ti}\right){ }^{\star} \operatorname{SIN}\left(\left(\mathrm{Zi}{ }^{\star} \Pi И()\right) /\right. \\
\left./\left(2^{\star} 180\right)\right)\end{array}$ & $\Delta \mathrm{H}^{1}=2 \sqrt{\mathrm{C}_{1}^{\prime} \mathrm{C}_{2}^{\prime}} \sin \left(\Delta \mathrm{h}^{\prime} / 2\right)$ \\
\hline 19 & $\begin{array}{c}=1+\left(0,015^{\star}(\mathrm{Li}-50)^{\star}(\mathrm{Li}-\right. \\
50)) /\left(\mathrm{KOPEHb}\left(20+(\mathrm{Li}-50)^{\star}(\mathrm{Li}-50)\right)\right)\end{array}$ & $\mathrm{S}_{\mathrm{L}}=1+\frac{0.015\left(\overline{\mathrm{L}^{\prime}}-50\right)^{2}}{\sqrt{20+\left(\overline{\mathrm{L}}^{\prime}-50\right)^{2}}}$ \\
\hline 20 & $=1+0,045^{\star} \mathrm{Ui}$ & $\mathrm{S}_{\mathrm{c}}=1+0.045 \overline{\mathrm{C}}^{\prime}$ \\
\hline 21 & $=1+0,015^{\star} \mathrm{Ui}^{\star} \mathrm{Yi}$ & $\mathrm{S}_{\mathrm{H}}=1+0.015 \overline{\mathrm{C}}^{\prime} \mathrm{T}$ \\
\hline 22 & $\begin{array}{c}=30 \star \text { EXP }(- \text { CTЕПЕНЬ }((X i- \\
275) / 25 ; 2))\end{array}$ & $\Delta \theta=30 \exp \left\{-\left(\frac{\overline{\mathrm{H}}^{\prime}-275^{\circ}}{25}\right)^{2}\right\}$ \\
\hline 23 & $\begin{aligned}= & \text { КОРЕНЬ(СТЕПЕНЬ(Ui;7)/(CTE } \\
& \text { ПЕНЬ(Ui;7)+СТЕПЕНЬ(25;7))) }\end{aligned}$ & $\mathrm{R}_{\mathrm{C}}=\sqrt{\frac{\overline{\mathrm{C}}^{/ 7}}{\overline{\mathrm{C}}^{/ 7}+25^{7}}}$ \\
\hline 24 & $=-2^{\star} \mathrm{AHi}{ }^{\star} \operatorname{SIN}\left(2^{\star} \mathrm{AGi}\right)$ & $\mathrm{R}_{\mathrm{T}}=-2 \mathrm{R}_{\mathrm{C}} \sin (2 \Delta \theta)$ \\
\hline 25 & $\begin{array}{l}1 \\
1 \\
1\end{array}$ & $\begin{array}{l}\mathrm{K}_{\mathrm{L}}=1 \text { default } \\
\mathrm{K}_{\mathrm{C}}=1 \text { default } \\
\mathrm{K}_{\mathrm{H}}=1 \text { default }\end{array}$ \\
\hline 26 & $\begin{array}{c}=\left(\left(A A i /\left(A J i{ }^{\star} A D i\right)\right)^{\wedge} 2+\left(A B i /\left(A K i{ }^{\star} A E i\right.\right.\right. \\
))^{\wedge} 2+\left(A C i /\left(A L i{ }^{*} A F i\right)\right)^{\wedge} 2+A l i{ }^{\star}(A B i /(A \\
\\
\left.\left.\left.\quad K i^{\star} A E i\right)\right)^{\star}\left(A C i /\left(A L i^{\star} A F i\right)\right)\right)^{\wedge} 0,5\end{array}$ & $\Delta \mathrm{E}=\sqrt{\begin{array}{l}\left(\frac{\Delta \mathrm{L}^{\prime}}{\mathrm{K}_{\mathrm{L}} \cdot \mathrm{S}_{\mathrm{L}}}\right)^{2}+\left(\frac{\Delta \mathrm{C}^{\prime}}{\mathrm{K}_{\mathrm{C}} \cdot \mathrm{S}_{\mathrm{C}}}\right)^{2}+ \\
+\left(\frac{\Delta \mathrm{H}^{\prime}}{\mathrm{K}_{\mathrm{H}} \cdot \mathrm{S}_{\mathrm{H}}}\right)^{2}+\mathrm{R}_{\mathrm{T}} \cdot \\
\left(\frac{\Delta \mathrm{C}}{\mathrm{K}_{\mathrm{C}} \cdot \mathrm{S}_{\mathrm{C}}}\right) \cdot\left(\frac{\Delta \mathrm{H}^{\prime}}{\mathrm{K}_{\mathrm{H}} \cdot \mathrm{S}_{\mathrm{H}}}\right)\end{array}}$ \\
\hline
\end{tabular}


Dot Gain $=\frac{R_{0}-R_{N}}{R_{0}-R_{100}} \times 100-N$ де параметр $\mathrm{R}$ для друку CMYK фарбами може бути виражено через колірні координати в системі XYZ у такій відповідності: Cyan - X, Magenta $-Y$, Yellow Z, Black - Y.

Згідно концепції побудови середовища Microsoft Excel обчислення для кожного з кольорів плашок табл. 3 (для кольору Cyan) виконується автоматично на окремих програмних аркушах.

Побудова програмних засобів формування звіту якості кольоровідтворення виконується на основі мови програмування

Visual Basic for Application рис. 2. В розробленому програмному забезпеченні формується звіт з визначеними статистичними розрахунками та проводиться аналіз якості кольоровідтворення на основі порівняння отриманих значень кольорового відхилення CIE $\Delta \mathrm{E} 2000$ з рекомендованими значеннями міжнародного стандарту ISO 12647-2: 2008. При невідповідності якості кольоровідтворення стандарту ISO 12647-2: 2008 звіт надає можливість своєчасного обґрунтування для корегування технологічного процесу підготовки та друку, що дозволяє зменшити

Таблиця 2

Уніфіковані програмні засоби розрахунку похибки вимірювання для плашок кольорів у середовищі Microsoft Excel

\begin{tabular}{|c|c|c|}
\hline № & Формула Microsoft Excel & Аналітичний вираз згідно з СIE 2000 \\
\hline 1 & $=\mathrm{CP} 3 \mathrm{HAЧ}\left(\mathrm{AM}_{\mathrm{i}}: \mathrm{AM}_{\mathrm{i}+8}\right)$ & $\langle x\rangle=\frac{1}{n} \sum_{i=1}^{n} x_{i}$ \\
\hline 2 & $=\operatorname{CУMM}\left(\mathrm{AO}_{\mathrm{i}}: \mathrm{AO}_{\mathrm{i}+8}\right) / 72$ & $S_{n}=\sqrt{\frac{\sum_{i=1}^{n}\left(\langle x\rangle-x_{i}\right)^{2}}{n-1}}$ \\
\hline 3 & $A Q_{i}=0,99, A R_{i}=3,4$ & $\mathrm{t}_{0.99,9}=3,4$ \\
\hline 4 & $=A R_{i}^{*} A P_{i}$ & $\Delta \mathrm{x}_{\text {вип }}=\mathrm{t}_{\alpha, \mathrm{n}} \cdot \mathrm{S}$ \\
\hline 5 & $A T_{i}=0,02$ & $\Delta \mathrm{x}_{\text {cuct }}=0,02$ \\
\hline 6 & $=$ CTEПЕНЬ $\left(A S_{i}^{*} A S_{i}+A T_{i}^{*} A T_{i} ; 0,5\right)$ & $\Delta \mathrm{x}=\sqrt{\Delta \mathrm{x}_{\text {вип }}^{2}+\Delta \mathrm{x}_{\text {сист }}^{2}}$ \\
\hline 7 & $=A N_{i}+A U_{i}$ & $x=\langle x\rangle+\Delta x$ \\
\hline
\end{tabular}


Таблиця 3

Уніфіковані програмні засоби розрахунку розтискування для кольору Cyan у середовищі Microsoft Excel

\begin{tabular}{|c|c|c|}
\hline № & Формула Microsoft Excel & Аналітичний вираз згідно з СІE 2000 \\
\hline 1 & $\begin{array}{c}=\text { ЕСЛИ }\left(C_{i}>\text { KAPPA_ETA; }\left(\left(C_{i}+16\right)^{\star}\right.\right. \\
\left.\left.\star\left(C_{i}+16\right)^{\star}\left(C_{i}+16\right)\right) / 1560896 ; C_{i} / \text { KAPPA }\right)\end{array}$ & $y_{r}=\left\{\begin{array}{cc}((L+16) / 116)^{3} & L>\kappa \varepsilon \\
L / \kappa & L \leq \kappa \varepsilon\end{array}\right.$ \\
\hline 2 & $\begin{aligned}=\text { ЕСЛИ }\left(\mathrm{H}_{\mathrm{i}}>\mathrm{ETA} ;\left(\mathrm{C}_{\mathrm{i}}+16\right) / 116 ;\right. \\
\\
\left.\quad\left(\text { KAPPA* }^{\star} \mathrm{H}_{\mathrm{i}}+16\right) / 116\right)\end{aligned}$ & $f_{y}=(L+16) / 116$ \\
\hline 3 & $=D_{i}^{\star} 0,002+14$ & $f_{x}=\frac{a}{500}+f_{y}$ \\
\hline 4 & $=J_{i}{ }^{*} J_{i}{ }^{*} J_{i}$ & $f_{x}^{3}$ \\
\hline 5 & $=E С Л И\left(\mathrm{~K}_{\mathrm{i}}<=\mathrm{ETA} ;\left(116^{\star} \mathrm{J}_{\mathrm{i}}-16\right) / \mathrm{KAPPA} ; \mathrm{K}_{\mathrm{i}}\right)$ & $x_{r}=\left\{\begin{array}{cc}f_{x}^{3} & f_{x}^{3}>\varepsilon \\
\left(116 f_{x}-16\right) / \kappa & f_{x}^{3} \leq \varepsilon\end{array}\right.$ \\
\hline 6 & $=\mathrm{l}_{\mathrm{i}}-\left(\mathrm{E} 4^{\star} 0,005\right)$ & $f_{z}=f_{y}-\frac{b}{200}$ \\
\hline 7 & $=\mathrm{M}_{\mathrm{i}}^{\star} \mathrm{M}_{\mathrm{i}}^{\star} \mathrm{M}_{\mathrm{i}}$ & $f_{z}^{3}$ \\
\hline 8 & $\begin{array}{c}=\text { EСЛИ }\left(\mathrm{N}_{\mathrm{i}}<=\text { ETA; }\left(116^{\star} \mathrm{M}_{\mathrm{i}^{-}}\right.\right. \\
\left.16) / \text { KAPPA; } \mathrm{N}_{\mathrm{i}}\right)\end{array}$ & $z_{r}=\left\{\begin{array}{cc}f_{z}^{3} & f_{x}^{3}>\varepsilon \\
\left(116 f_{z}-16\right) / \kappa & f_{x}^{3} \leq \varepsilon\end{array}\right.$ \\
\hline 9 & $=\mathrm{L}_{\mathrm{i}} / \mathrm{D} 50 \mathrm{X}$ & $X=x_{r} X_{r}$ \\
\hline 10 & $=\mathrm{H}_{\mathrm{i}} / \mathrm{D} 50 \mathrm{Y}$ & $Y=y_{r} Y_{r}$ \\
\hline 11 & $=\mathrm{O}_{\mathrm{i}} / \mathrm{D} 50 \mathrm{Z}$ & $\mathrm{Z}=\mathrm{z}_{\mathrm{r}} \mathrm{Z}_{\mathrm{r}}$ \\
\hline 12 & $=100^{\star}\left(\left(1-\left(\mathrm{P}_{\mathrm{i}} / \$ \mathrm{P} \$_{\mathrm{i}}\right)\right) /\left(1-\left(\$ \mathrm{P} \$_{\mathrm{i}+10} / \$ \mathrm{PP} \$_{\mathrm{i}}\right)\right)\right)-\mathrm{B}_{\mathrm{i}}$ & Dot Gain $=\frac{R_{0}-R_{N}}{R_{0}-R_{100}} \times 100-N$ \\
\hline
\end{tabular}


Аналіз результатів кольоровідтворення:

Dim myRange As Range

Dim cell As Range

Set myRange = ThisWorkbook.Sheets("output").Range("F10:F18")

For Each cell In myRange

If cell.Value = "Добре" Then

cell. Interior.Colorlndex $=34$

cell. Font.Colorlndex $=25$

End If

If cell.Value $=$ "Допустиме" Then

cell. Interior.ColorIndex $=27$

cell. Font.Colorlndex $=46$

End If

If cell.Value = "Недопустиме" Then

cell.Interior.ColorIndex $=3$

cell.Font.Colorlndex $=9$

End If

Next

Створення вихідного файла з результатами:

'dd = ThisWorkbook.Sheets("output").cell(2, 3).Value

'ThisWorkbook.Sheets("output").cell(2, 3).Value = dd

ThisWorkbook.Sheets("output").Visible = True

Dim nb As Workbook, s As String

$\mathrm{s}=$ ThisWorkbook. FullName

$s=\operatorname{Left}(s, \operatorname{Len}(s)-4)$ \& "2.xIs"

ThisWorkbook.Sheets("output").Copy

Set $\mathrm{nb}=$ ActiveWorkbook

ThisWorkbook.Sheets("output").Visible = False

End Sub

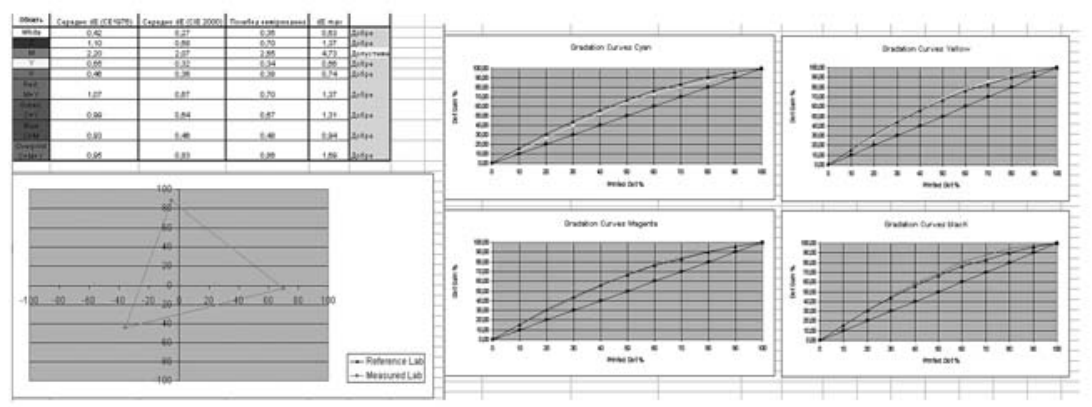

Рис. 2. Формування звіту та проведення аналізу якості кольоровідтворення на мові VBA 
брак продукції на основі аналізу представлених графіків кольорового охоплення та розтискування та прийняття рішення оперативного керування кольором.

Програмне забезпечення складається 3 аналізу результатів цифрової статистичної обробки кольорових характеристик та формується у вигляді інтегрованих висновків аналітичних розрахунків середнього значення $\Delta \mathrm{E}$, похибки вимірювання та логічного висновку кольоровідтворення для досліджуваного друкарського аркуша.

Для забезпечення керування кольором у випадку незадовільних результатів процесу кольоровідтворення на основі отриманих кольорових характеристик Lab координат обчислюється на основі розробленої програми розтискування Dot Gain за інтерпретованою формулою Мюррея-Девіса. Аналіз розтискування проводиться по графікам розтискування для кожної з тріадних фарб окремо.

\section{Висновки}

1. Застосування структурної організації програмно-технічних засобів для реалізації прикладного програмного забезпечення керування вимірюваннями, обробкою та аналізом процесів кольоровідтворення дозволяє мінімізувати загальний час процесів керування кольором офсетного способу друку у декілька разів, за рахунок процесів цифрового визначення якості кольоровідтворення та сприяє підвищенню якості друкованої продукції.

2. Об'єктивність процесів вимірювання характеристик кольоровідтворення на основі цифрової обробки інформації, з використанням процедурноорієнтованої технологій опису процесів в єдиному інформаційному середовищі та її реалізація, надає перспективи побудови систем аналізу якості кольоровідтворення по новій концепції, що дозволить значно підвищити ефективність процесів керування кольором у реальному масштабі часу.

1. Ефимов М. В. Автоматизация технологических процессов полиграфии / М. В. Ефимов, Г. Д. Толстой. - М. : Книга, 1989. - 512 с. 2. Киппхан Г. Энциклопедия по печатным средствам информации. - М. : МГУП, 2003. - C. 1280. 3. Hunt R. W. G. The Reproduction of Colour: Sixth Edition / R. W. G. Hunt. - The Wiley-IS\&T Series in Imaging Science and Technology, 2004. - 724 p. 4. ColorPort Basic User Guide v1.5.2. Руководство X-Rite. USA: X-Rite Incorporated. - 2007. - 5 c. 5. Курбатова Е. A. Microsoft Office Excel 2010. Самоучитель / Е. А. Курбатова. - К. : Диалектика, Вильямс, 2010. - 416 с. 6. Кузьменко В. Г. VВА / В. Г. Кузьменко. - М. : Бином-Пресс, 2008. $-624 \mathrm{c}$. 